Research Article

\title{
Characterizing Repeats in Two Whole-Genome Amplification Methods in the Reniform Nematode Genome
}

\author{
S. T. Nyaku $\mathbb{D}^{1}{ }^{1}$ V. R. Sripathi, ${ }^{2}$ K. Lawrence, ${ }^{3}$ and G. Sharma ${ }^{2}$ \\ ${ }^{1}$ Department of Crop Science, College of Basic and Applied Sciences, University of Ghana, Legon, P.O. Box LG44, Ghana \\ ${ }^{2}$ Department of Biological and Environmental Sciences, Alabama A \& M University, Normal AL 35762, USA \\ ${ }^{3}$ Department of Entomology and Plant Pathology, Auburn University, Auburn, AL 36849, USA
}

Correspondence should be addressed to S. T. Nyaku; seloame.nyaku@gmail.com

Received 14 January 2021; Accepted 26 February 2021; Published 8 March 2021

Academic Editor: Kacper Zukowski

Copyright (c) 2021 S. T. Nyaku et al. This is an open access article distributed under the Creative Commons Attribution License, which permits unrestricted use, distribution, and reproduction in any medium, provided the original work is properly cited.

One of the major problems in the U.S. and global cotton production is the damage caused by the reniform nematode, Rotylenchulus reniformis. Amplification of DNA from single nematodes for further molecular analysis can be challenging sometimes. In this research, two whole-genome amplification (WGA) methods were evaluated for their efficiencies in DNA amplification from a single reniform nematode. The WGA was carried out using both REPLI-g Mini and Midi kits, and the GenomePlex single cell whole-genome amplification kit. Sequence analysis produced $4 \mathrm{Mb}$ and $12 \mathrm{Mb}$ of genomic sequences for the reniform nematode using REPLI-g and SIGMA libraries. These sequences were assembled into 28,784 and 24,508 contigs, respectively, for REPLI-g and SIGMA libraries. The highest repeats in both libraries were of low complexity, and the lowest for the REPLI-g library were for satellites and for the SIGMA library, RTE/BOV-B. The same kind of repeats were observed for both libraries; however, the SIGMA library had four other repeat elements (Penelope (long interspersed nucleotide element (LINE)), RTE/BOV-B (LINE), PiggyBac, and Mirage/P-element/Transib), which were not seen in the REPLI-g library. DNA transposons were also found in both libraries. Both reniform nematode $18 \mathrm{~S}$ rRNA variants (RN_VAR1 and RN_VAR2) could easily be identified in both libraries. This research has therefore demonstrated the ability of using both WGA methods, in amplification of gDNA isolated from single reniform nematodes.

\section{Introduction}

The reniform nematode is most commonly found within the southern parts of U.S. and is also in many tropical and subtropical regions of the world [1]. Areas within the U.S. where this nematode has established include Alabama, Florida, Arkansas, Hawaii, Louisiana, Georgia, Mississippi, South Carolina, North Carolina, and Texas. This nematode has surpassed the root-knot nematode (Meloidogyne incognita) in Alabama, Louisiana, and Mississippi as the leading pest of upland cotton [2].

Development of whole-genome amplification (WGA) techniques for amplification of DNA from nanogram quantities has aided the success of most genetic research which once needed microgram quantities. These methods prove very useful in applications such as forensic science, embryonic disease diagnosis, microbial diversity, bioterrorism genome detection, and genotyping [3] and especially in sequencing genomes of single nematodes. Two of the most used WGA techniques include multiple-displacement amplification (MDA) and Omniplex methods. The MDA method utilizes $\varphi 29$ DNA polymerase, which is highly processive, and the activities of random exonuclease-resistant primers, in the amplification reaction [4]. In the Omniplex technique, the genomic DNA is fragmented into smaller fragments (e.g., 200-2000 bases) for the generation of a library, which is then amplified. A high-fidelity polymerase is involved in the reaction which enables the library to be amplified several thousand folds. Whole-genome sequencing has been successfully used in sequencing of two human parasitic nematodes, including Wuchereria bancrofti [5] and Strongyloides stercoralis [6]. The usefulness of whole-genome amplification methods has been applied in genome sequencing projects for the reniform nematode $[7,8]$. 
Existence of low-complexity regions (LCRs) [9] and their repeats $(2.2 \%)$ within the genome of reniform nematode serves as an indication of higher levels of variation [8].

The objectives of this study were to characterize repeats in the reniform nematode genome through massively parallel genome sequencing, when two different whole-genome amplification (WGA) methods were employed.

\section{Materials and Methods}

Eggs of the reniform nematode were extracted from the roots of MicroTom tomato plants and were sterilized by immersion in $10 \%$ Clorox solution and then shaken continually for 4 minutes in a beaker. The solution was then poured through a 325-mesh sieve, nested on a 500-mesh sieve. The eggs were rinsed thrice with distilled water into a $10 \mathrm{ml}$ beaker, to remove the residues of Clorox solution.

A 325-mesh sieve and a 500-mesh sieve were sterilized by autoclaving using the dry cycle $\left(120^{\circ} \mathrm{C}\right.$ for $\left.1 \mathrm{hr}\right)$. Extracted reniform eggs were then poured onto the 325-mesh sieve nested on the 500-mesh sieve. Clorox solutions of concentrations $0.5 \%, 5 \%$, and $10 \%$ were used for sterilizing the eggs. The eggs on the 500-mesh sieve were rinsed immediately with about $300 \mathrm{ml}$ of sterilized distilled water to wash off the Clorox solution for about 5 minutes and then transferred into sterilized beakers with about $10 \mathrm{ml}$ of sterilized distilled water. One $\mathrm{ml}$ of the solution containing the sterilized eggs was placed onto the agar plates. These plates were sealed with parafilm along its edges, covered with aluminum foil, and then kept at room temperature for 2 to 4 days for the eggs to hatch. Some of the plates were also placed in the incubator set at $25^{\circ} \mathrm{C}$ for hatching of the eggs.

Extraction of DNA was initially from fourteen (14) single sterilized female reniform nematodes, undertaken using the DNeasy blood and tissue kit (Qiagen, Maryland, USA) according to the manufacturer's recommended protocol. Two (2.0) $\mu \mathrm{l}$ of extracted DNA $(\sim 1 \mathrm{ng} / \mu \mathrm{l})$ was transferred into PCR tubes containing $2.5 \mu \mathrm{l} 10 \mathrm{x}$ buffer (Promega, Madison, WI, USA), $2.0 \mu \mathrm{l} \mathrm{MgCl}_{2}$ (25 mM) (Promega, Madison, WI, USA), $0.5 \mu \mathrm{l}$ dNTPs $(10 \mathrm{mM}), 0.5 \mu \mathrm{l}$ of primer $(10 \mu \mathrm{m})$ (synthesized by MWG-Biotech AG, USA), and $0.2 \mu \mathrm{l}$ of Taq DNA polymerase (Promega, Madison, WI, USA), and the required amount of double distilled water was added to make up the final volume to $25 \mu \mathrm{l}$. Primers $18 \mathrm{SF}$ ( $5^{\prime}$ GCTTGTCTC AAAGATTAAGCC- $3^{\prime}$ ) and 18SR ( $5^{\prime}$-TGATCCWKCYGCAGGTTCAC- $3^{\prime}$ ) which amplified the $5^{\prime}$ one-third of the $18 \mathrm{~S}$ rRNA gene used in the amplifications. Polymerase chain reaction (PCR) was performed in a Peltier Thermal Cycler (PTC) tetrad 2 DNA engine (Bio-Rad, Hercules, CA, USA). Polymerase chain reaction conditions were as follows: $95^{\circ} \mathrm{C}$ for $5 \mathrm{~min}$, then 30 cycles of the following: $95^{\circ} \mathrm{C}$ for $30 \mathrm{sec}$, $57^{\circ} \mathrm{C}$ for $30 \mathrm{sec}$, and $72^{\circ} \mathrm{C}$ for $45 \mathrm{sec}$. The final extension phase was $72^{\circ} \mathrm{C}$ for $5 \mathrm{~min}$. The quality of PCR products was checked by gel electrophoresis of $6 \mu \mathrm{l}$ of PCR reaction on $1 \%$ agarose gel with ethidium bromide staining. The bands were visualized and photographed under ultraviolet light. The size of each PCR product was determined by comparing it to a $100 \mathrm{bp}$ DNA marker.
In order to verify the absence of bacterial contamination, DNA isolated from the nematodes was amplified using the universal bacterial primers to amplify the $16 \mathrm{~S} \mathrm{rDNA}$ region. Extracted DNA $(2 \mu \mathrm{l} ; \sim 1 \mathrm{ng} / \mu \mathrm{l})$ was transferred into PCR tubes containing $2.5 \mu \mathrm{l} \mathrm{10x}$ buffer (Promega, Madison, WI, USA.), $2.0 \mu \mathrm{lgCl}_{2}$ (25 mM) (Promega, Madison, WI, USA.), $0.5 \mu \mathrm{ldNTPs}(10 \mathrm{mM}), 0.5 \mu \mathrm{l}$ of primer $(10 \mu \mathrm{m})$ (synthesized by MWG-Biotech AG, USA), and $0.2 \mu \mathrm{l}$ of Taq DNA polymerase (Promega, Madison, WI, USA.), and double distilled water added to a final volume of $25 \mu \mathrm{l}$. Primers PRBA338F ( $5^{\prime}$ AC TCC TAC GGG AGG CAG CAG $3^{\prime}$ ) (Lane, 1991) and PRUN518R (5' ATT ACC GCG GCT GCT GG 3') [10] were used in the amplifications. The PRBA338F and PRUN518R primers amplify the 338 to 518 rDNA region and contain one variable loop of rRNA. A positive control (Pseudomonas DNA) and a negative control (DNase-free water) were included in the amplifications. PCR reactions were performed in a Peltier Thermal Cycler (PTC) tetrad 2 DNA engine (Bio-Rad, Hercules, CA, USA). PCR conditions were as follows: $94^{\circ} \mathrm{C}$ for $9 \mathrm{~min}$, then touched down using $9 \mathrm{cycles}$ from $62^{\circ} \mathrm{C}$ for $30 \mathrm{sec}$ to $57^{\circ} \mathrm{C}$ for $30 \mathrm{sec}$ and 29 cycles of the following: $94^{\circ} \mathrm{C}$ for $30 \mathrm{sec}, 57^{\circ} \mathrm{C}$ for $30 \mathrm{sec}$, and $72^{\circ} \mathrm{C}$ for $30 \mathrm{sec}$. The final extension phase was $72^{\circ} \mathrm{C}$ for $7 \mathrm{~min}$. The quality of PCR products was checked by electrophoresis of $6 \mu \mathrm{l}$ of PCR reaction in $1 \%$ agarose gel with ethidium bromide staining. The gel was visualized and photographed under ultraviolet light, and the size of each PCR product was determined by comparing it with a 100 bp DNA marker.

PCR products from seven individual female nematodes were cloned into a plasmid vector using TOPO TA Cloning Kit (Invitrogen-Life Technologies, Carlsbad, CA). The ligation reaction was made up of $3 \mu \mathrm{l}$ of PCR product, $1 \mu \mathrm{l}$ of salt solution $\left(1.2 \mathrm{M} \mathrm{NaCl}\right.$ and $\left.0.06 \mathrm{M} \mathrm{MgCl}_{2}\right), 1 \mu \mathrm{l}$ of sterile water, and $1 \mu \mathrm{l}$ of TOPO vector. Several clones were picked for verification of inserts from PCR amplifications conducted, using each nematode clonal DNA with M13 forward and reverse primers. PCR conditions were as follows: $94^{\circ} \mathrm{C}$ for $5 \mathrm{~min}$, then 40 cycles of the following: $94^{\circ} \mathrm{C}$ for $30 \mathrm{sec}, 55^{\circ} \mathrm{C}$ for $1 \mathrm{~min}$, and $72^{\circ} \mathrm{C}$ for $1 \mathrm{~min}$. The final extension phase was $72^{\circ} \mathrm{C}$ for $10 \mathrm{~min}$. Individual colonies were picked and placed in separate $1.5 \mathrm{ml}$ centrifuge tubes with $1 \mathrm{ml}$ of liquid $\mathrm{LB}$ media containing $100 \mu \mathrm{g} / \mathrm{ml}$ of ampicillin. These were shaken at $37^{\circ} \mathrm{C}$ for 24 hours at $300 \mathrm{rpm}$ in an Innova 4300 rotary incubator shaker (New Brunswick Scientific, Edison, NJ). Tubes containing the bacterial cells were centrifuged for 30 seconds at 13,000 rpm in a Hermle MR-2 (National Labnet Company, Woodbridge, NJ) tabletop centrifuge to obtain a cell pellet. Plasmid DNA was isolated using a QIAprep Miniprep kit (QIAGEN, Maryland, USA).

Plasmid inserts from at least ten colonies originating from each individual nematode were sequenced in both directions with two vector primers, M13 F and M13R, using the Applied Biosystems (ABI) PRISM BigDye Terminator cycle sequencing ready reaction kit (Applied Biosystems, Foster City, CA) in an ABI 3100 nucleotide sequencer in the Center for Molecular Biology at Alabama A \& M University. The sequences were then screened for homology, to reniform nematode sequences using the standard 
nucleotide-nucleotide BLAST (blastn) on the NCBI website (http://www.ncbi.nlm.nih.gov). Sequences from nematodes having high homology to reniform nematode sequences in the GenBank were identified, and the DNA from these nematodes used for whole-genome amplification (WGA), following the manufacturer's protocol.

The DNA of four female reniform nematodes was used for WGA after confirmation of the absence of bacterial contamination. The WGA was carried out using both REPLI-g Mini and Midi kits (Qiagen, Maryland, USA), as well as the GenomePlex single cell whole-genome amplification (WGA4) kit (Sigma-Aldrich, MO, USA). Procedures for amplifications were followed according to the manufacturer's protocol. Concentrations of amplicons were determined using a TKO 100 fluorometer (Hoefer Scientific Instruments, San Francisco). The PCR products obtained from both WGA methods were further amplified using $18 \mathrm{~S}$ and bacterial primers. Real-time PCR was then used to validate results obtained from WGA amplifications using 16S rRNA genespecific primers in the Roche LightCycler 480 instrument (Indianapolis, IN, USA) to check for any bacterial contamination. Whole-genomic-amplified DNA was purified using the GenElute PCR clean-up kit (Sigma-Aldrich, MO, USA) and then quantified using a TKO 100 fluorometer (Hoefer Scientific Instruments, San Francisco).

Purified gDNA libraries $(10 \mu \mathrm{g} / \mu \mathrm{l})$ from pooled DNA of selected four single female reniform nematodes were used in 454 high-throughput sequencing at the Advanced Centre for Genome Technology (ACGT), University of Oklahoma (Norman, OK).

Gene Ontology (GO) distributions for the reniform nematode genomic sequences were determined using Blast2GO (http://www.blast2go.com) a functional annotation and visualization tool.

\section{Results}

Amplification using 18S rRNA primers produced a $600 \mathrm{bp}$ band for all the 14 female reniform nematodes (Figure 1). The positive control (Pseudomonas DNA) amplified a $200 \mathrm{bp}$ band; however, all the reniform nematode samples including the negative control (DNase-free water) showed no amplifications (Figure 2).

Whole-genome amplification (WGA) performed on four selected female nematodes, using the REPLI-g and SIGMA kits, showed distinct amplifications (Figures 3 and 4).

Real-time PCR analysis confirmed Pseudomonas DNA (positive control) as of a bacterial origin with the highest concentration, but no evidence of bacterial contamination was detected from the reniform nematode DNA (data not shown).

A total of $4 \mathrm{Mb}$ and $12 \mathrm{Mb}$ of sequence data generated from the REPLI-g and SIGMA genomic libraries were constructed from the reniform nematodes (RN). In order to reduce data redundancy, the sequences were assembled for quality and length improvements, generating 28,784 and 24,508 contigs for the REPLI-g and SIGMA libraries, respectively, using the Lasergene software (Table 1).

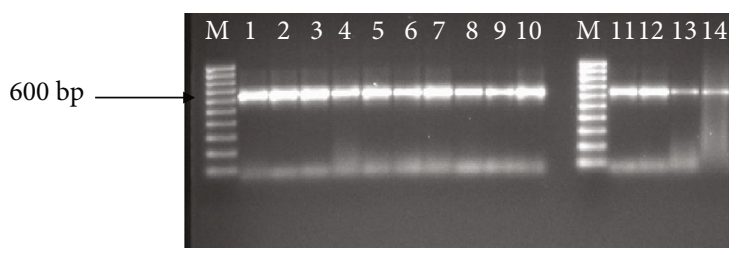

Figure 1: Amplification of 14 female reniform nematodes using $18 \mathrm{~S}$ rRNA primers showing a $600 \mathrm{bp}$ band. M: $100 \mathrm{bp}$ molecular marker.

Repeat masker (http://www.repeatmasker.org/cgi-bin/ WEBRepeatMasker) was used in characterization of the reniform nematode genome from each of the libraries and to study its organization (Tables 2 and 3), for REPLI-g and SIGMA libraries, respectively. The highest and lowest numbers of repeats within the genome of RN from the REPLI-g library were low-complexity repeats (87\%) occupying a region of $130,763 \mathrm{bp}$ and satellites $(<1 \%)$, occupying a region of $320 \mathrm{bp}$. Simple repeats were the second highest (6\%) within the reniform nematode genome occupying a 10,584 bp region. However, the reniform nematode SIGMA genomic library had retrotransposable (RTE)/Bovine-B (Bov-B) repeats being the lowest in the genome $(<1 \%)$ and occupying a region of $66 \mathrm{bp}$. The highest repeats from this library were the same as those from the REPLI-g library; these were low-complexity repeats (86\%), occupying a region of $304,237 \mathrm{bp}$, and the next highest repeats were simple repeats $(7.2 \%)$; these occupied a 32,111 bp region.

A comparison of the genome characteristics using the repeat masker showed that the SIGMA library had four other repeat elements (Penelope (long interspersed nucleotide elements (LINE)), RTE/BOV-B PiggyBac, and Mirage/P-element/Transib); these were absent in the library generated using REPLI-g. The reniform nematode $18 \mathrm{~S}$ rRNA variants RN_VAR1 and RN_VAR2 [11] were used in blastn analysis against the assembled reniform nematode 454 genome sequences (Table 4). A combined total of 19 hits were noted in both variants to the 454 genome sequences, and 5 contigs from the genomic sequences fully overlapped for the coverage of the full $18 \mathrm{~S}$ rRNA gene.

Gene Ontology (GO) analysis performed on both genomic libraries were grouped by molecular function, biological process, and cellular component. By molecular function, ten major GO distributions were assigned with a minimum of 200 sequences with an assigned gene function for the SIGMA library. These were protein binding, ATP binding, transporter activity, transcription factor activity, binding, DNA binding, protein binding, iron ion binding, oxidoreductase activity, catalytic activity, and zinc ion binding with 875 , $405,400,276,274,255,255,225,212$, and 210 sequences, respectively. The percentage contributions by each of these functions are shown (Figure 5). Similarly, ten major GO distributions were observed by molecular function for the REPLI-g library. These were protein binding, DNA binding, ATP binding, nucleic acid binding, GTP binding, catalytic activity, GTPase activity, structural molecule activity, RNAdirected DNA polymerase activity, and RNA binding. These 


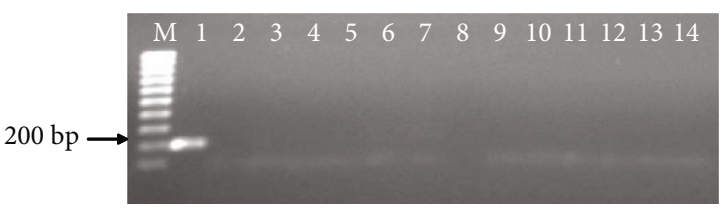

Figure 2: Amplification of 14 female reniform nematodes using bacterial primers. M: $100 \mathrm{bp}$ marker; 1: Pseudomonas DNA (+ve control); 2: sterilized DNAse-free water (-ve control); 3-14 are reniform nematode amplifications.

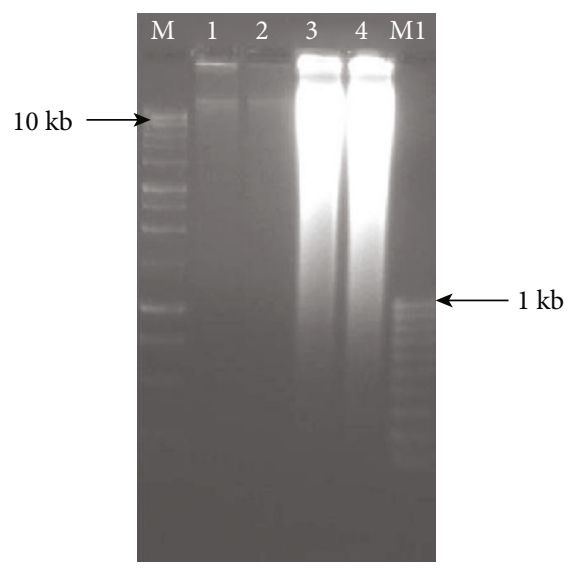

FIgURE 3: Whole-genome amplification (WGA) of 4 female reniform nematodes using REPLI-g Mini and Midi kits. M: $1 \mathrm{~kb}$ marker; M1: $00 \mathrm{bp}$ marker; 1: $2.5 \mu \mathrm{l}(26 \mathrm{ng} / \mu \mathrm{l})$ of DNA using the Mini kit; 2: $5.0 \mu \mathrm{l}(26 \mathrm{ng} / \mu \mathrm{l})$ of DNA using the Mini kit; 3: $2.5 \mu \mathrm{l}$ $(560 \mathrm{ng} / \mu \mathrm{l})$ of DNA using the Midi kit; 4: $5.0 \mu \mathrm{l}(775 \mathrm{ng} / \mu \mathrm{l})$ of DNA using the Midi kit).

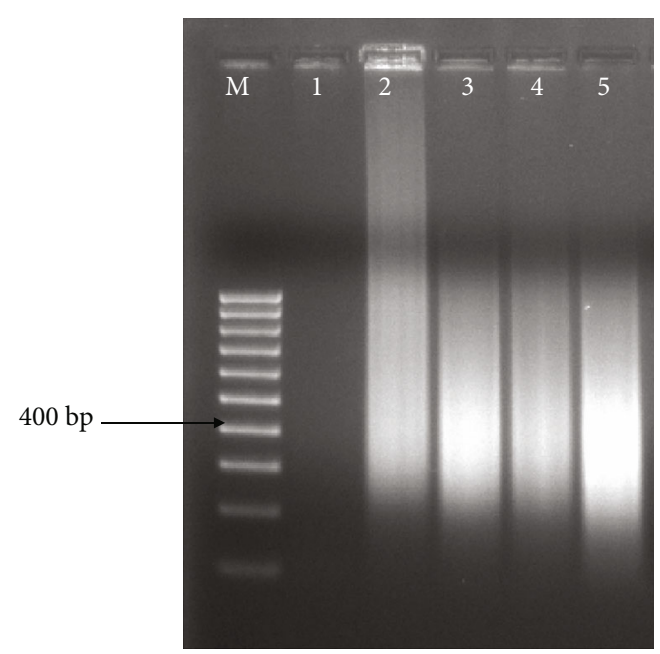

FIGURE 4: Whole-genome amplification (WGA) of 4 female reniform nematodes using SIGMA kit. M: 100 bp marker; 1: -ve control (no DNA); 2: +ve control (human genomic DNA_D7192)$45 \mathrm{ng} / \mu \mathrm{l}$; 3: RN DNA sample $1 \mathrm{~A}(143 \mathrm{ng} / \mu \mathrm{l}), 4$ : RN DNA sample 12A (145 ng/ $\mu \mathrm{l})$; 5: RN DNA sample 13A (134 ng/ $\mu \mathrm{l})$.

had $25,25,18,14,8,6,5,5,5$, and 5 sequences contributing to these functions. The percentage contributions by each of these functions are shown (Figure 6).
TABLE 1: Reniform nematode assembly characteristics for REPLI-g and SIGMA genomic libraries.

\begin{tabular}{lcc}
\hline Assembly characteristics & REPLI-g & SIGMA \\
\hline Total number of contigs & 28,784 & 24,508 \\
Assembly combined length & $4,418,499 \mathrm{bp}$ & $12,732,631 \mathrm{bp}$ \\
$\begin{array}{l}\text { Number of sequences < 200 bp } \\
\text { Number of sequences between }\end{array}$ & 21,125 & 1903 \\
$200 \mathrm{bp} \& 1 \mathrm{~kb}$ & 7656 & 20,305 \\
$\begin{array}{l}\text { Number of sequences between } \\
1 \mathrm{~kb} \& 5 \mathrm{~kb}\end{array}$ & 3 & 2243 \\
$\begin{array}{l}\text { Number of sequences between } \\
5 \mathrm{~kb} \& 10 \mathrm{~kb}\end{array}$ & 0 & 57 \\
\hline
\end{tabular}

TABLE 2: Summary of repeats within the reniform nematode genome using the REPLI-g library.

\begin{tabular}{lcc}
\hline Type of element & No. of elements & Length occupied (bp) \\
\hline Retroelements & 50 & 5682 \\
L2/CRI/Rex (LINEs) & 8 & 608 \\
BEL/Pao (LTR) & 6 & 305 \\
Gypsy/DIRS1 (LTR) & 36 & 4769 \\
DNA transposons & 70 & 5188 \\
$\quad$ Hobo-activator & 10 & 829 \\
Tc1-IS630-Pogo & 47 & 3615 \\
MuDR-IS905 & 8 & 490 \\
Unclassified & 6 & 447 \\
Small RNA & 39 & 6023 \\
Satellites & 2 & 320 \\
Simple repeats & 231 & 10,584 \\
Low complexity & 3311 & 130,763 \\
\hline Total & 3824 & 169,623 \\
\hline
\end{tabular}

By biological process, eight major GO distributions were observed, each had a minimum of 100 sequences, contributing to that function or annotation for the SIGMA library. These include regulation of transcription, transport, metabolic process, electron transport, two-component signal transduction system, proteolysis, peptidyl-histidine phosphorylation, and signal transduction with $637,585,525$, $412,262,175,125$, and 110 sequences, respectively. The percentage contributions by each of these processes are shown (Figure 7). However, by biological process, seven major GO distributions were rather observed for the REPLI-g library, each of which had a minimum of 9 sequences contributing to that function or annotation. These were nematode larval development, reproduction, positive regulation of growth, embryonic development, regulation of transcription, DNA metabolic process, and locomotion with 15, 14, 13, 13, 11, 10 , and 9 sequences, respectively. The percentage contributions by each of these processes are shown (Figure 8).

By cellular component, seven major GO distributions were observed for the SIGMA library, each of which had a minimum of 100 sequences contributing to that function or 
TABLE 3: Summary of repeats within the reniform nematode genome using the SIGMA genomic library.

\begin{tabular}{lcc}
\hline Type of element & No. of elements & Length occupied (bp) \\
\hline Retroelements & 79 & 12,340 \\
Penelope (LINEs) & 2 & 227 \\
L2/CRI/Rex (LINEs) & 26 & 2956 \\
RTE/BOV-B (LINEs) & 1 & 66 \\
BEL/Pao (LTR) & 5 & 251 \\
Gypsy/DIRS1 (LTR) & 45 & 8840 \\
DNA transposons & 79 & 6882 \\
$\quad$ Hobo-activator & 13 & 1045 \\
$\quad$ Tc1-IS630-Pogo & 47 & 4716 \\
$\quad$ MuDR-IS905 & 7 & 322 \\
PiggyBac & 2 & 103 \\
Other (Mirage, & 2 & 105 \\
P-element, Transib) & 36 & 6549 \\
Unclassified & 121 & 24,200 \\
Small RNA & 8 & 1785 \\
Satellites & 491 & 32,111 \\
Simple repeats & 5890 & 304,237 \\
Low complexity & 6854 & 406,735 \\
\hline Total & & \\
\hline
\end{tabular}

TABLE 4: Summary of blast hits among reniform nematode $18 \mathrm{~S}$ variants and 454 genomic sequences.

\begin{tabular}{lcc}
\hline RN 18S rRNA variant & $\begin{array}{c}\text { REPLI-g 454 } \\
\text { sequences }\end{array}$ & $\begin{array}{c}\text { SIGMA 454 } \\
\text { sequences }\end{array}$ \\
\hline Total number of hits (RN_VAR1) & 54 & 244 \\
$\begin{array}{l}\text { Overlapping contigs } \\
\text { (nonredundant) (RN_VAR1) }\end{array}$ & 16 & 16 \\
$\begin{array}{l}\text { Total number of hits (RN_VAR2) } \\
\text { Overlapping contigs } \\
\text { (nonredundant) (RN_VAR2) }\end{array}$ & 56 & 244 \\
\hline
\end{tabular}

annotation. These were integral to membrane, cytoplasm, membrane, plasma membrane, intracellular membrane, cell outer membrane, and outer membrane-bound periplasmic space with $1,000,575,540,425,250,145$, and 100 sequences, respectively. The percentage contributions by each of these components are also presented for detailed examination (Figure 9). The REPLI-g library however had ten major GO distributions for the cellular component, each of which had a minimum of 3 sequences contributing to that function or annotation. Their organellar and membrane-bound distributions were cytoplasm, integral to membrane, mitochondrion, membrane, nucleus, endoplasmic reticulum, transcription factor complex, inclusion body, ribosome, and plasma membrane with $17,11,11,8,5,4,3,3,3$, and 3 sequences, respectively. The percentage contributions by each of these components are also presented (Figure 10).

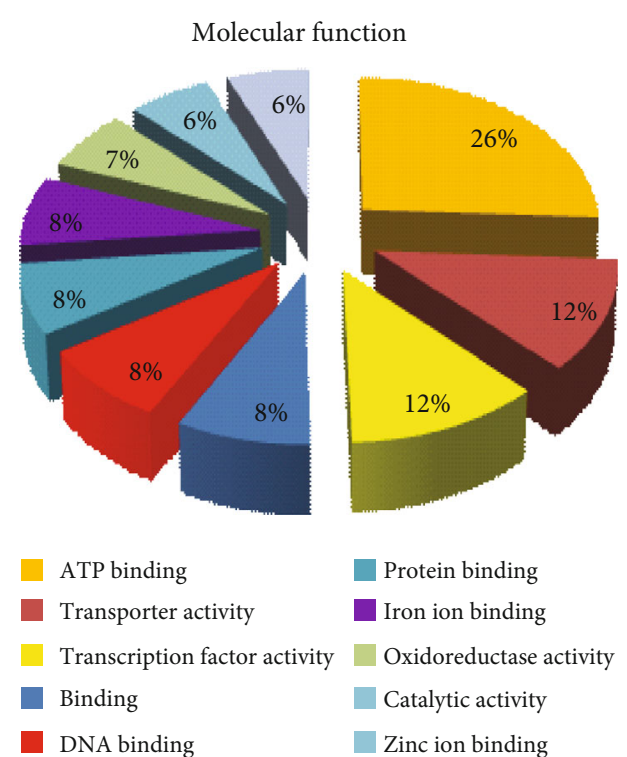

FIgURE 5: Gene Ontology (GO) distributions for reniform nematode genomic sequences as determined by Blast $2 \mathrm{GO}$ and grouped by molecular function for the SIGMA library.

\section{Discussion}

Mobile genetic elements (retrotransposons) have the ability of generating DNA through reverse transcription of RNA; this DNA is then inserted into the eukaryotic genome. The horizontal gene transfer between bird and nematode genomes took place in two pantropical waves, 425-22 million years ago (Myr ago) involving the Brugia/Wuchereria lineage and 420-17 Myr ago involving the Loa lineage [12]. A number of these elements were observed within both genomic libraries of the reniform nematode. Classes of retrotransposons include long-terminal-repeat (LTR) retrotransposons; these elements have mechanisms possessed by vertebrate retroviruses. Elements BEL/Pao and Gypsy/DIRS1 were present in both genomic libraries of the reniform nematode. Depending on the type of reverse transcriptase (RT) domain possessed by the LTR retrotransposons, these were categorized into Ty1/copia, Bel, and Ty3/gypsy groups. In Saccharomyces cerevisiae, Ty1 and Ty3 are very well studied and characterized; on the other hand, copia, Bel, and Gypsy are found in Drosophila melanogaster.

Another group is the tyrosine recombinase retrotransposons which have similar properties to those of LTR retrotransposons; however, they possess integrase instead of recombinase, as they integrate into the host chromosomes. The second group is the non-LTR retrotransposons, which do not possess either inverted or tandem terminal repeats; these have poly $(\mathrm{A})$ tails at their $3^{\prime}$ ends, and their $5^{\prime}$ ends have variable deletions ( $5^{\prime}$ truncations). These elements encode open reading frames (ORFs), which are prone to mutations [13]. Examples of these elements are LINEs (long interspersed nucleotide elements), which are autonomous and about $5-10 \mathrm{~kb}$ in length; the other is SINEs (short 


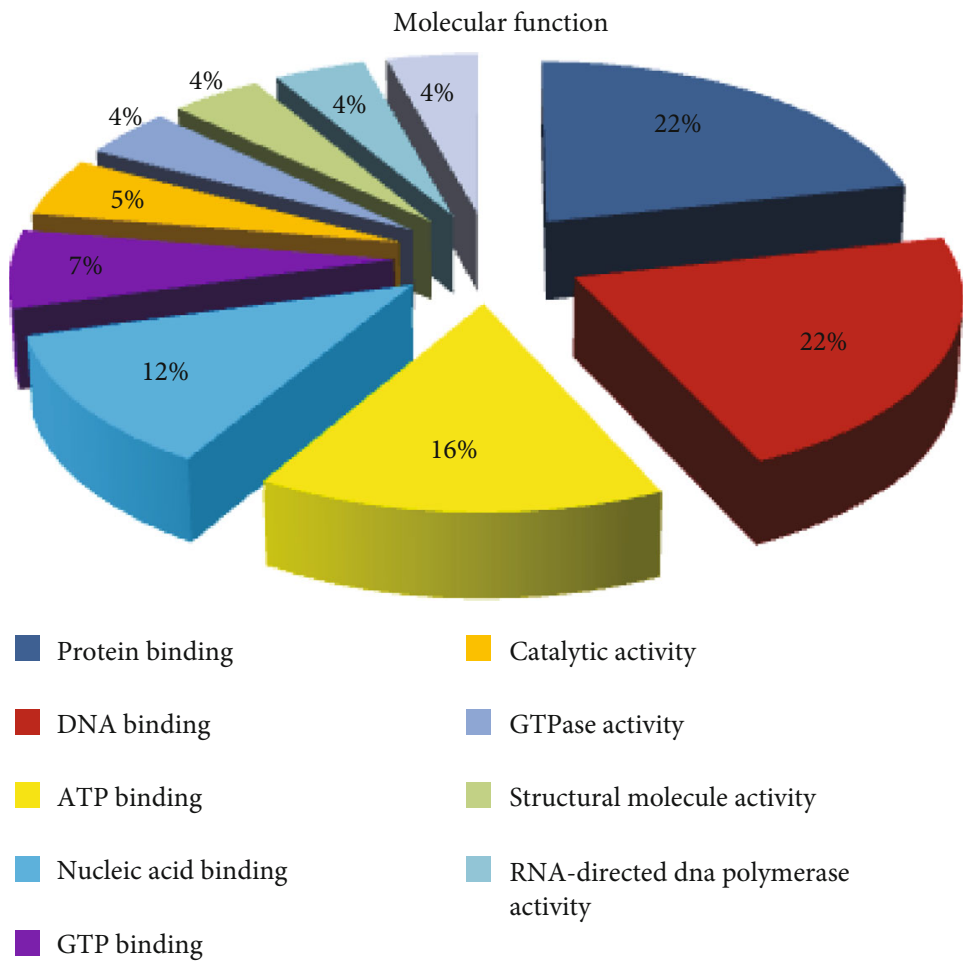

FIGURE 6: Gene Ontology (GO) distributions for reniform nematode genomic sequences as determined by Blast2GO and grouped by molecular function for the REPLI-g library.

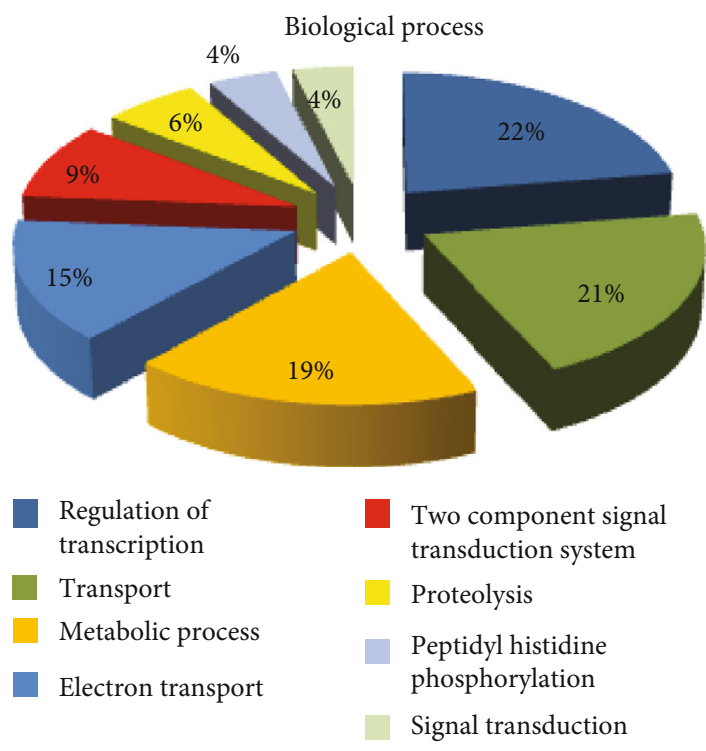

FIgURE 7: Gene Ontology (GO) distributions for reniform nematode genomic sequences as determined by Blast2GO and grouped by biological process for the SIGMA library.

interspersed nucleotide elements), which are nonautonomous and about 100-400 bp in length [14]. The Penelopelike retrotransposons and LINEs found in Drosophila virilis [15]. This element inserts into the host genome and their structures that are very diverse compared to other classes of retrotransposons. These elements have the Uri domain
(GIY-YIG), and for reverse transcription, they make use of the ends of chromosomes to serve as primers. Two Penelope-like retrotransposons were identified in only the SIGMA genomic library of the reniform nematode. The third group of transposable elements is DNA transposons; these have short terminal inverted repeats (TIRs) of about 2$10 \mathrm{bp}$ at their terminals, with a long ORF, which codes for protein domains possessing transposase (TR) and DNA binding mechanisms. These elements were present in both genomic libraries of the reniform nematode. Transposable elements could either be autonomous (1000-4000 bp) or nonautonomous (100-3000 bp); i.e., an example is Miniature Inverted Repeat Transposable elements (MITEs). Transposition of DNA transposons occurs in a variety of ways; however, their duplications occur when DNA is being replicated [16]. The "cut-and-paste" mode of action is usually utilized during DNA transposition in majority of eukaryotes; here, the element is cleaved and transported to another location by the TR. However, the rolling circle (RC) mechanism is used by other eukaryotic elements during DNA transposition; this is similar to that occurring in prokaryotes [17]. In a recent study, DNA transposons or LTR retroelements (20.6 Mb and $11.3 \mathrm{Mb}$, respectively) were identified in reniform nematode genomic assembly (RREN1.0, GCA 001026735.1) of size $314 \mathrm{Mb}$ [8].

The majority of repeats within both reniform nematode genomic libraries were low-complexity repeats $(>86 \%)$. Low-complexity regions (LCRs) occur in many genomes and among protein families [9]. The diversity occurring among the amino acid sequences of these regions is low, 


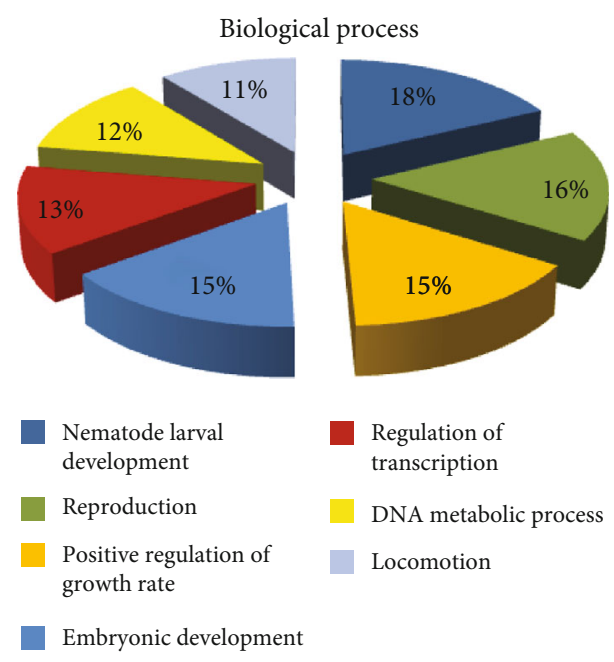

FIgURE 8: Gene Ontology (GO) distributions for reniform nematode genomic sequences as determined by Blast2GO and grouped by biological process for the REPLI-g library.

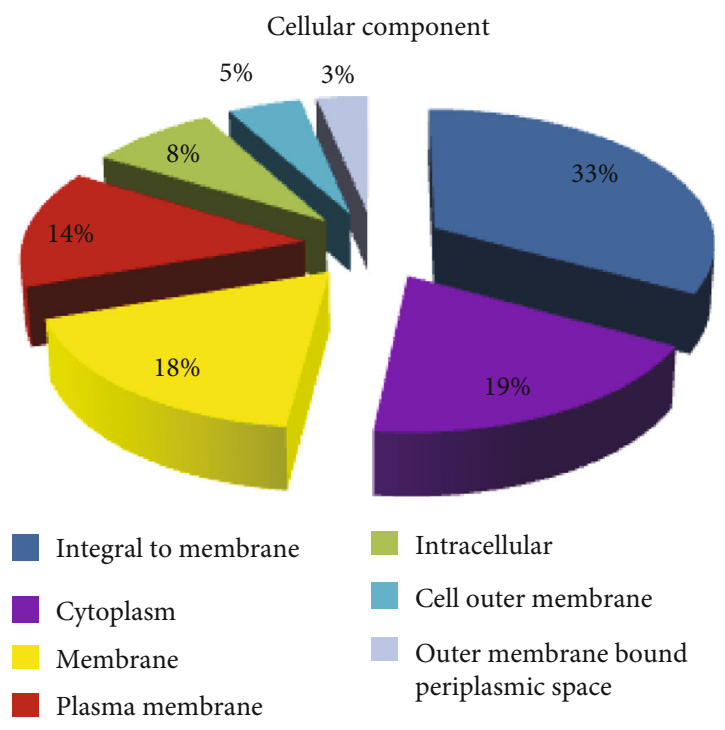

Figure 9: Gene Ontology (GO) distributions for reniform nematode genomic sequences as determined by Blast2GO and grouped by cellular component for the SIGMA library.

and any variation occurring may range from areas with one or many amino acids at specific positions [18]. Meiotic recombination has been implicated in the fast evolutions of LCRs [19]. Repeats are also present in genomes of prokaryotes, contributing to genetic variations in these organisms [20]. The highest source of variation in LCRs is from the tandem repeats which could expand and contract [21]. The prevalence of high low-complexity repeats within the reniform nematode genome suggests high levels of variation in its genome. These low-complexity repeats occupied about $2.2 \%$ of the reniform genome [8].

Simple repeats were the next highest repeats within the reniform nematode genome; these were about $6 \%$ and $7.2 \%$ of total repeats for the REPLI-g and SIGMA libraries. These

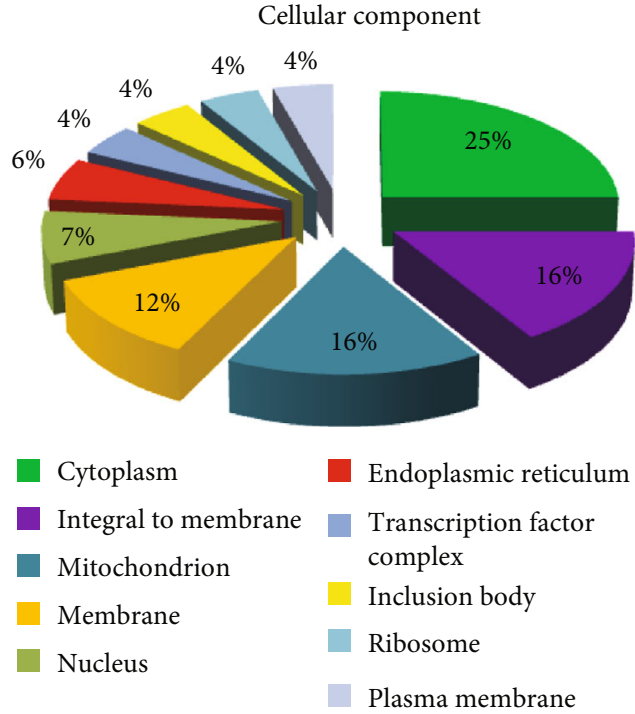

Figure 10: Gene Ontology (GO) distributions for reniform nematode genomic sequences as determined by Blast2GO and grouped by cellular component for the REPLI-g library.

simple repeats could be either be microsatellites or minisatellites. Microsatellites contribute to evolution within organisms [22] and are also subjected to changes in their lengths (replication slippage). Replication slippage does not occur frequently; its occurrence is once every 1,000 generations [23]. The presence of simple repeats in the reniform nematode genome may serve as markers for the identification of resistance in plants attacked by this nematode. Another transposon identified in the SIGMA library is the PiggyBac transposon. This has been used in transposon mutagenesis in insects (e.g., Drosophila melanogaster). The Piggyback transposase activity was observed in D. melanogaster when the mutator elements in this organism present on the $\mathrm{X}$ chromosome in males were used in providing this activity through a Hermes-based jump starter element; the $\alpha$-1-tubulin promoter was used in this process [24]. In transposon mutagenesis, transposal elements are able to insert themselves into genomic loci resulting in gene disruption.

\section{Conclusion}

This research has revealed the ability of using both WGA methods in amplification of gDNA from individual reniform nematodes with both techniques useful in increasing DNA concentrations and identification of repeats, which can also be applied in other species of nematodes. The highest repeats in both libraries were low complexity; however, the lowest repeats for the REPLI-g and SIGMA libraries were satellites and $\mathrm{RTE} / \mathrm{BOV}-\mathrm{B}$ repeats, respectively.

\section{Data Availability}

The raw reads for $\mathrm{RN}$ genomic sequences were submitted to the NCBI Sequence Read Archive (accession Nos. SRX099033 and SRX099034) for REPLI-g and SIGMA libraries, respectively. 


\section{Conflicts of Interest}

The authors declare that there are no conflicts of interest regarding the publication of this article.

\section{Acknowledgments}

This work was supported by USDA-CSREES grant \# 200438814-15160 and ALAX-011-706 to Ramesh V. Kantety, ALAX-011-206 to Govind C. Sharma, and NSF Plant Genome Research award \# 0703470 to Ramesh V. Kantety. This study is dedicated to the late Dr. Ramesh V. Kantety.

\section{References}

[1] R. F. Davis, S. R. Koenning, R. C. Kemerait, T. D. Cummings, and W. D. Shurley, "Rotylenchulus reniformis management in cotton with crop rotation," Journal of Nematology, vol. 35, no. 1, pp. 58-64, 2003.

[2] A. F. Robinson, "Reniform in U.S. cotton: when, where, why, and some remedies," Annual Review of Phytopathology, vol. 45, no. 1, pp. 263-288, 2007.

[3] T. L. Hawkins, J. C. Detter, and P. M. Richardson, "Whole genome amplification - applications and advances," Current Opinion in Biotechnology, vol. 13, no. 1, pp. 65-67, 2002.

[4] F. B. Dean, S. Hosono, L. Fang et al., "Comprehensive human genome amplification using multiple displacement amplification," Proceedings of the National Academy of Sciences, vol. 99, no. 8, pp. 5261-5266, 2002.

[5] S. T. Small, L. J. Reimer, D. J. Tisch et al., "Population genomics of the filarial nematode parasite Wuchereria bancrofti from mosquitoes," Molecular Ecology, vol. 25, no. 7, pp. 1465-1477, 2016.

[6] T. Kikuchi, A. Hino, T. Tanaka et al., "Genome-wide analyses of individual Strongyloides stercoralis (Nematoda: Rhabditoidea) provide insights into population structure and reproductive life cycles," PLoS Neglected Tropical Diseases, vol. 10, no. 12, article e0005253, 2016.

[7] S. T. Nyaku, V. R. Sripathi, R. V. Kantety et al., "Characterization of the reniform nematode genome by shotgun sequencing," Genome, vol. 57, no. 4, pp. 209-221, 2014.

[8] K. C. Showmaker, W. S. Sanders, S. Eves-van den Akker et al., "A genomic resource for the sedentary semi-endoparasitic reniform nematode, Rotylenchulus reniformis Linford \& Oliveira," Journal of Nematology, vol. 51, pp. 1-2, 2019.

[9] A. Coletta, J. W. Pinney, D. Y. Solís, J. Marsh, S. R. Pettifer, and T. K. Attwood, "Low-complexity regions within protein sequences have position-dependent roles," BMC Systems Biology, vol. 4, no. 1, 2010.

[10] G. Muyzer, E. C. De Waal, and A. G. Uitterlinden, "Profiling of complex microbial populations by denaturing gradient gel electrophoresis analysis of polymerase chain reactionamplified genes coding for 16S rRNA," Applied and Environmental Microbiology, vol. 59, no. 3, pp. 695-700, 1993.

[11] S. T. Nyaku, V. R. Sripathi, R. V. Kantety, Y. Q. Gu, K. Lawrence, and G. C. Sharma, "Characterization of the two intra-individual sequence variants in the $18 \mathrm{~S}$ rRNA gene in the plant parasitic nematode, Rotylenchulus reniformis," PLoS One, vol. 8, no. 4, article e60891, 2013.

[12] A. C. C. Suh, J. Witt, K. Menger et al., "Ancient horizontal transfers of retrotransposons between birds and ancestors of human pathogenic nematodes," Nature Communications, vol. 7 , no. 1,2016 .

[13] T. H. Eickbush and V. K. Jamburuthugoda, "The diversity of retrotransposons and the properties of their reverse transcriptases," Virus Research, vol. 134, no. 1-2, pp. 221-234, 2008.

[14] H. Tang, "Genome assembly, rearrangement, and repeats," Chemical Reviews, vol. 107, no. 8, pp. 3391-3406, 2007.

[15] M. B. Evgen'ev, H. Zelentsova, N. Shostak et al., "Penelope, a new family of transposable elements and its possible role in hybrid dysgenesis in Drosophila virilis," Proceedings of the National Academy of Sciences, vol. 94, no. 1, pp. 196-201, 1997.

[16] J. F. Y. Brookfield, “Transposable elements as selfish DNA," in Mobile Genetic Elements, D. J. Sherratt, Ed., IRL Press, Oxford, 1995.

[17] V. V. Kapitonov and J. Jurka, "Rolling-circle transposons in eukaryotes," Proceedings of the National Academy of Sciences, vol. 98, no. 15, pp. 8714-8719, 2001.

[18] M. DePristo, M. Zilversmit, and D. Hartl, "On the abundance, amino acid composition, and evolutionary dynamics of lowcomplexity regions in proteins," Gene, vol. 378, pp. 19-30, 2006.

[19] E. M. Marcotte, M. Pellegrini, H. L. Ng, D. W. Rice, Yeates TO, and D. Eisenberg, "Detecting protein function and proteinprotein interactions from genome sequences," Science, vol. 285, no. 5428, pp. 751-753, 1999.

[20] E. R. Moxon, P. B. Rainey, M. A. Nowak, and R. E. Lenski, "Adaptive evolution of highly mutable loci in pathogenic bacteria," Current Biology, vol. 4, no. 1, pp. 24-33, 1994.

[21] J. Fondon and H. Garner, "Molecular origins of rapid and continuous morphological evolution," Proceedings of the National Academy of Sciences, vol. 101, no. 52, pp. 18058-18063, 2004.

[22] M. D. Vinces, M. Legendre, M. Caldara, M. Hagihara, and K. J. Verstrepen, "Unstable tandem repeats in promoters confer transcriptional evolvability," Science, vol. 324, no. 5931, pp. 1213-1216, 2009.

[23] J. L. Weber and C. Wong, "Mutation of human short tandem repeats," Human Molecular Genetics, vol. 2, no. 8, pp. 11231128, 1993.

[24] C. Horn, N. Offen, S. Nystedt, U. Hacker, and E. A. Wimmer, "piggyBac-based insertional mutagenesis and enhancer detection as a tool for functional insect genomics," Genetics, vol. 163, no. 2, pp. 647-661, 2003. 